\title{
A miséria da teoria em Geografia
}

\author{
The misery of theory in Geography
}

\author{
Elias Lopes de Lima \\ Doutor em Geografia, \\ Professor do Programa de Pós-Graduação em Geografia da UFJF, Brasil \\ Pesquisador do Núcleo de Pesquisa Geografia, Espaço e Ação - NuGea \\ elias.lopes@ufjf.edu.br
}

\begin{abstract}
Resumo
O presente artigo objetiva explicitar alguns obstáculos pelos quais passa a produção teórica na ciência geográfica na atualidade. Presume-se que a geografia sofre de um relativo esvaziamento teórico-conceitual no decurso hodierno da sua produção científica. Tal esvaziamento, contudo, não deve ser levado ao pé da letra. Não se sugere, exatamente, que aportes teórico-conceituais não estejam sendo empreendidos na contemporaneidade, mas sim que os mesmos se apresentam de maneira frágil e superficial. Para alcançar o aludido objetivo e sustentar tal assertiva, partiremos de três premissas, quais sejam: 1. as implicações do positivismo na produção teórica da geografia, no tocante às tentativas de especialização da teoria geográfica; 2. os impactos do caráter efêmero e não raro infundado de visões e discursos pós-modernos e culturalistas na produção do conhecimento; 3 . as implicações do modelo de produção científica orientado pelas políticas de fomento à pesquisa para a reflexão e a formulação teórica.
\end{abstract}

Palavras-chave: Teoria da geografia, epistemologia, positivismo, pós-modernismo, políticas de fomento à pesquisa.

\begin{abstract}
This article aims to exhibit some obstacles faced by the theoretical production in Geographic Science at the current moment. It is assumed that Geography suffers a relative theoric-conceptual emptiness in today's course of its scientific production. Such emptiness, however, must not be taken in a literal manner. It is not precisely suggested that theoric-conceptual contributions are not being undertaken in modern days, but that they look fragile and superficial. In order to reach the stated objective and support such assertive, we will start from three premises which are: 1. The implications of the positivism in the theoretical production in Geography regarding the specialisation attempts of geographic theory; 2. The impacts of the ephemeral and, not rarely, unfounded nature of visions, and postmodern and cultural discourses in the production of knowledge; 3. The implications of the scientific production model recommended by research promotion policies intended for theory reflection and elaboration.
\end{abstract}

Keywords: Theory of geography, epistemology, positivism, postmodernism, research promotion policy.

\section{INTRODUÇÃO}

Há pouco mais de 40 anos, em 1978, o historiador marxista Edward Thompson (1981) publicava um livro de alentado teor epistêmico intitulado A miséria da teoria ou um planetário de erros: uma crítica ao pensamento de Althusser. Como o seu subtítulo anuncia, a obra explicita uma "letargia conceitual" resultante do peso do estruturalismo althusseriano na ordem do saber, em 
especial no âmbito do materialismo histórico e da historiografia. Thompson avalia que o materialismo histórico passara a repousar, a partir da intervenção de Althusser e de seus seguidores, "num frágil e corroído pilar epistemológico" (p. 10), cujo efeito mais (in)consequente foi a condenação do objeto da história a um embaraçoso empirismo. Com esses apontamentos preliminares, o historiador inglês pretende contribuir para o resgate do edifício dialético que fundamenta a concepção histórica do marxismo.

Nossa proposta com essas breves linhas, contudo, não é tão ambiciosa. A despeito de tomarmos de empréstimo uma parte do título daquela obra para sugerir uma crítica à produção teórica na geografia, não pretendemos revisitar os inconvenientes do estruturalismo e seus impactos na produção do conhecimento geográfico. Tampouco se propõe retomar os problemas da historiografia a guisa de um reflexo dos problemas teóricos da geografia. Convenhamos que a geografia possui massa crítica suficiente para refletir e reavaliar seu próprio "planetário de erros". A miséria da teoria, de Thompson, serve, para os fins desse trabalho, senão como uma inspiração: além do título, dela tiraremos proveito do espírito dialético que a motiva.

É bem verdade que o empirismo encontra solo ainda mais fértil na geografia do que na ciência histórica: se nesta o empirismo é levado a efeito pelo estruturalismo; naquela, sua gênese se perde na reconstrução do conhecimento e do próprio tempo. Sua presença na geografia é mais duradoura e, pode-se mesmo admitir, constitui um traço indelével. Não por acaso, o caráter empirista da geografia é sempre evocado quando o tema em apreço é a presumível fragilidade teórico-conceitual da geografia. Todavia, para efeito de evidenciar uma suposta fragilidade teórica, interessa-nos dar ênfase menos ao empirismo, enquanto corrente científico-filosófica, do que ao teor pragmático e/ou utilitarista presente na produção científica geográfica e nas relações cotidianas.

Uma das causas e ao mesmo tempo uma decorrência desse pragmatismo ordinário é, seguramente, (1) o peso do ideal fragmentário positivista em nossa visão de mundo e, em especial, na produção científica. Outra consequência verifica-se (2) no caráter utilitarista do discurso pósmoderno, manifestado no deliberado desapego de princípios e fundamentações gerais, sobretudo de matiz teórico-conceitual. Um terceiro aspecto constata-se (3) nas implicações das políticas de fomento científico para a produção teórica, a qual é submetida aos mesmos critérios de produtividade dispensados às pesquisas aplicadas. Compete-nos, a título de objetivo, discutir como essas determinações de ordem epistêmica, cultural e institucional replicam em alguns obstáculos pelos quais passa atualmente a produção teórica na ciência geográfica.

Dentre esses obstáculos, presentes de forma mais ou menos explícita em cada uma daquelas causas e/ou consequências, destacam-se: (i) a admissão equívoca da teoria da geografia como uma especialidade no interior do quadro setorizado de disciplinas geográficas; (ii) a negligência em relação às matrizes filosóficas que dão sustentação epistemológica aos conceitos e 
categorias; (iii) a subordinação de discursos e conceitos geográficos a aportes teórico-conceituais de outros ramos científicos por ocasião da problematização de temas afins; (iv) a redução do debate teórico a um apanhado historicista dos conceitos geográficos, ignorando-se, mais uma vez, sua condição epistemológica; por fim, (v) o impasse entre teoria e prática concernente à inconsistência na aplicação dos conceitos em face de problemas reais.

Para todos os efeitos, advertimos que essa sistematização não é de modo nenhum exaustiva, de maneira que outras variáveis poderiam muito bem vir em auxílio das ponderações que se seguem.

\section{DAS IMPLICAÇÕES DO POSITIVISMO}

Um dos impactos mais marcantes do positivismo para a teoria é a sua redução a uma causa explicativa, o que decorre da atribuição de uma causalidade a determinado aspecto de um fenômeno mediante um procedimento indutivo. Tal aspecto é alçado a tanto a partir da identificação de sua regularidade, após ser submetido a uma série de repetições exaustivas, as quais revelam uma variedade de outros aspectos inconstantes, tornados então manifestações residuais. A explicação se limita, portanto, a uma causalidade arbitrária, excluindo a multiplicidade em favor da unidade, com o agravante de estender tais condições a todos os ramos científicos. Porém, sem viabilizar uma interlocução entre os mesmos devido a sua constituição fragmentária.

A ausência de diálogo teórico entre os grandes campos científicos e, sobretudo, entre os domínios setorizados internos a uma ciência é, sem dúvida, a consequência mais emblemática do positivismo para a teoria. Se cada especialidade do quadro sistemático de uma ciência elege um objeto próprio, se não um método específico, acatando, com isso, uma exigência do positivismo, não há, ao fim e ao cabo, possibilidades de interlocução. Assim, cada ramo sistemático concebe seu arcabouço conceitual com base em seus princípios causais, objetos e escopo específicos, de maneira a reforçar sua especialização e contribuir para a fragmentação do real.

Consideramos, contudo, que o princípio de causalidade e o ideal fragmentário já foram suficientemente explorados e por isso não nos estenderemos nesses aspectos do positivismo. Interessa-nos mais pontuar os inconvenientes de assumir a teoria, ela própria, como uma especialidade.

De tão acostumados que estamos a interpretar, desde a mais tenra idade, praticamente tudo de forma fragmentada, habituados a ordenar as coisas que comparecem ao nosso discernimento de maneira setorizada, pouco nos damos conta de que a teoria geográfica não pode ser uma especialidade entre outras. Tal impossibilidade deriva da constatação de que a teoria é transversal e intrínseca a toda produção científica. Ela é um requisito indispensável a todas as especialidades, não 
podendo ser ela mesma, portanto, uma especialidade sob o risco de se esvaziar em seus propósitos epistemológicos e em sua natureza analítico-sintética.

Não obstante, a impressão irrefletida de que a teoria geográfica compõe uma subdisciplina da geografia deve-se, aparentemente, a uma necessidade de autoafirmação a qual reclama pra si uma identidade, uma especialidade. A impossibilidade de justificar os critérios de validade de seu edifício teórico nos termos do ideal fragmentário torna o "especialista em teoria”, desde logo, um “especialista de coisa-nenhuma" (MARTINS, 2016, p. 70). Isso não quer dizer que o improvável especialista não produza alguma teoria, embora ele comprometa tanto mais esse edifício quanto mais se volta para a própria teoria, esquecendo de todo o restante. É precisamente por fazer da teoria um fim em si mesma que sua prática se esvazia como "coisa-nenhuma".

Ademais, a teoria não é uma prerrogativa do suposto especialista. Se ele efetivamente a produz, não o faz mais que qualquer outro especialista da geografia, desde que este, é óbvio, reúna certas condições e se disponha a tanto. Tomemos o exemplo de três grandes teóricos da geografia brasileira: Milton Santos, Aziz Ab'Saber e Carlos Augusto F. Monteiro - respectivamente, um geógrafo urbano, um geomorfólogo e um climatólogo. Reconhecidos por sua contribuição teórica, nenhum deles era ou se assumia como especialista em teoria. E se acaso um ou outro autoproclamado teórico ganhe algum reconhecimento por sua produção teórica, não há nisso uma controvérsia mediante a constatação de que a teoria não se reduz a uma especialidade. Pelo contrário, confirma-se sua penetração por toda a geografia, o que não acontece necessariamente com a geografia urbana, a geomorfologia, a climatologia etc., a não ser por um esforço copioso de reintegração holista.

Todavia, pesa ao "especialista em teoria" a dificuldade de articular sua produção teórica com o pressuposto cientificista da aplicabilidade. Uma questão de método que realça o caráter mediador (fundamentador) da teoria. E disso se infere que ela é sempre um meio, jamais fim. Afinal, se o objeto do teórico é a própria teoria, conclui-se que o mesmo está teorizando, mais uma vez, sobre "coisa-nenhuma", posto que a teoria não cumpriria sua função de intermediar a explicação dos fatos e dos problemas colocados por seu próprio domínio científico. Martins (2016, p. 70) observa, a propósito, que “o sentido, a razão, o propósito da pesquisa teórica em geografia (...) são endógenos no seu sentido e importância”. Acomete ao inefável especialista uma espécie de ciclo vicioso que, mal comparando, se assemelha à imagem de um cão correndo atrás do próprio rabo. E disso se deduz porque boa parte dos trabalhos de teoria parece indiferente aos problemas de seu tempo. 


\section{DOS IMPACTOS DO PÓS-MODERNISMO}

A indiferença da teoria em relação aos problemas contemporâneos deriva, em parte, do caráter utilitarista típico das relações cotidianas num contexto de pós-modernidade. Não entraremos no mérito de definir a pós-modernidade e tampouco distingui-la de variáveis como modernidade tardia ou avançada e hipermodernidade. Até porque parece ser uma perda de tempo definir algo que por princípio não se atém a quaisquer princípios. Limitar-nos-emos a destacar que sua característica mais marcante é a da inconstância, a do caráter efêmero e fugidio dos acontecimentos. Sua retórica evoca um ecletismo em que nada é fundamentado. Sua narrativa é intertextual, segundo um cruzamento de olhares, porém sem contexto (MOREIRA, 2012).

A despreocupação em embasar certos argumentos e posições repercute num acentuado desdenho para com a teoria, considerando-a desnecessária porque desprovida supostamente de utilidade. "Há desqualificação do que é teórico, na suposição equivocada de que o teórico é destituído de prática; na suposição equivocada de que há o prático esvaziado de pensamento; na prevalência do discurso em prol da prática, na expectativa de que o prático seja mais útil” (HISSA, 2013, p. 76). Útil, nessa perspectiva, é o que tem valor imediato, de vez que a inconstância dos fatos inviabiliza, no plano da consciência, a sua permanência. A teoria torna-se, assim, se não um fardo, um mero capricho; utilizada, quando muito, como um expediente protocolar para fins de justificação científica.

Quando compelida a tanto, a postura pós-modernista dá margem ao emprego indiscriminado de conceitos, sem a adoção de quaisquer critérios para utilizá-los. Em geografia evoca-se, nessa perspectiva, o conceito de lugar quando dever-se-ia utilizar o de paisagem; espaço ao invés de território ou região e assim por diante. Não há, para todos os efeitos, a menor preocupação com suas respectivas vinculações ontológicas (com a práxis, os problemas e as questões que cada tempo e campo científico se propõem). Em muitos casos, alude-se ao conceito na sua forma vulgar: lugar e região são os mais requisitados, nesse sentido. Talvez em geografia esses desvios sejam mais sintomáticos, dada suas manifestações, diríamos, kantianas, isto é, de serem tomadas como impressões a priori.

A confusão é ainda maior quando se negligencia a subordinação dos conceitos às suas respectivas matrizes epistemológicas. O ecletismo característico dos dias atuais induz que, por ocasião da adoção de um determinado conceito, misturem-se aportes gestados no ambiente do materialismo dialético com aportes originados no âmbito da fenomenologia, do pós-estruturalismo, da semiologia etc. Nisso reside seu caráter intertextual, todavia, desprovido de contexto. Ignora-se que os problemas motivadores dos conceitos no interior de cada uma dessas matrizes são diferentes e em alguns casos até conflitantes, o que implica na não interação entre os conceitos, ainda que com 
a mesma terminologia. É como se dispuséssemos para dialogar indivíduos homônimos com domínios linguísticos diferentes: não se compreenderiam.

Em meio a esse cortejo de terminologias soltas (MOREIRA, 2014, p. 22), o próprio geógrafo parece não compreender seu "lugar de fala", expressão tão difundida entre os entusiastas do culturalismo pós-moderno. Diante de determinados temas, não é casual que se adote acriticamente alguns conceitos erigidos em outras ciências, esvaziando o próprio discurso geográfico e até mesmo o estatuto de cientificidade da geografia. Isso porque, ignora-se, mais uma vez, que os problemas e as inquietações no interior dos quais aqueles conceitos foram concebidos podem ser distintos e até divergentes das questões que motivam a geografia. Com isso, subutiliza-se o seu arcabouço teórico-conceitual, o qual comparece, quando muito, subordinado ao enfoque conceitual de outros campos científicos por ocasião da apreciação de temáticas afins à geografia (GUIMAR ÃES; LIMA, 2017).

A problemática ambiental talvez seja o exemplo mais eloquente, mas de modo nenhum o único. Ela é frequentemente tratada em geografia sob o corte conceitual habitual de outros domínios científicos, como ecossistema, entropia e sustentabilidade - para ficarmos com apenas três casos, cada qual concernente a um campo científico distinto: respectivamente, biologia, física e economia. Raramente essa temática é embasada sob a perspectiva dos processos de territorialização, de urbano-periferização ou de produção do espaço (PORTO-GONÇALVES, 2015). Quarenta anos após a fina crítica de Milton Santos (2012, p. 118), para quem "a geografia é viúva do espaço”, os geógrafos continuam a contrair dívidas com outros campos científicos. Sua base de ensino e de pesquisa, advertia Santos, é a historiografia, as ciências naturais e a economia neoclássica. Pouco parece ter mudado desde então.

A despeito da vigência de uma "virada espacial" (HARVEY, 1989), o geógrafo aparenta dificuldades para contribuir com propriedade teórica para os grandes debates da atualidade. Para se desembaraçar de tal inconveniente, ele apela para a diversidade de seu quadro temático, reclamando alguma autoridade para lidar com os mais distintos objetos. Todavia, esbarra no anacronismo do projeto de síntese da tradição geográfica, sabidamente uma proposta pobre de conceitos e de formulações teóricas. A debilidade teórica da geografia concorre para uma pueril identidade e um precário lócus de enunciação. E disso se infere sua inclinação à especialização e sua sujeição a categorias exteriores. Edificada sobre um frágil alicerce, a teoria geográfica cambaleia mediante o menor abalo, sem lastro para se sustentar face os desafios atuais. 


\section{DAS CONSEQUÊNCIAS DAS POLÍTICAS DE FOMENTO À PESQUISA}

Nos últimos anos, as políticas das instituições de fomento à pesquisa $\left(\mathrm{CAPES}^{1}, \mathrm{CNPq}^{2} \mathrm{e}\right.$ suas congêneres estaduais) imprimiram um renovado impulso à produção científica no Brasil. $\mathrm{O}$ Relatório Research in Brazil, produzido por analistas da agência de consultoria Clarivate Analytics (CROSS et al., 2018) para a CAPES, revela um expressivo desempenho da produção científica brasileira entre 2011 e 2016. Embora também demonstre que o impacto dessas publicações, medido pelo número de citações das mesmas, esteja aquém da média mundial, a despeito de ter aumentado em $15 \%$ no período avaliado. O tom entusiástico com que esses números são celebrados, adornados com gráficos coloridos e ascendentes (SOUZA NETO, 2013), contrasta com as evidências deletérias de seus efeitos para a produção científica.

A disputa por recursos estimulada pelos critérios de avaliação de produtividade adotados por essas agências, em especial a CAPES, tem implicado na baixa qualidade daquelas publicações, e disso deriva o reduzido impacto das mesmas. Nesse cenário, prioriza-se, em nome da "eficácia" (segundo um léxico nada estranho à dita eficiência de mercado), um número cada vez mais crescente de publicações viciadas (que pouco variam em conteúdo) em prejuízo de trabalhos mais consistentes que demandam maior tempo e investimento intelectual e metodológico. Com isso, multiplica-se e difunde-se o fenômeno salami science, prática de fatiar um trabalho mais denso e de maior impacto no maior número possível de artigos.

Embora não haja dados conclusivos sobre a produção geográfica sob tais condições, não são poucas as objeções a esse modelo de produção científica em geografia (SOUZA NETO, 2017; CORRÊA, 2006; SHORT, 2002; GIBSON; KLOCKER, 2004). Tais críticas evidenciam, entretanto, que o problema é menos de uma ou outra ciência específica do que uma questão de ordem estrutural. Em última análise, reiteramos, trata-se de uma política de produção científica subjacente à eficácia mercantil e financeira (SOUZA NETO, 2017). Disso deriva toda sorte de carreirismos, produtivismos, aparelhamentos e consequente concentração de poder nas mãos de um restrito punhado de pesquisadores (CORRÊA, 2006; SHORT, 2002).

Não é preciso esforço para constatar que nada de proveitoso em termos de produção teórico-conceitual pode florescer dessa política de pesquisa. Até porque os critérios de produtividade válidos para as ciências "duras" e aplicadas são os mesmos para as ciências sociais e, sobretudo, para seus estudos de cariz teórico. Todas as fragilidades teóricas apontadas até aqui são replicadas e algumas são ainda mais aprofundadas, pois a preocupação do pesquisador passa a ser menos o seu objeto de estudo e a produção do conhecimento do que a pontuação auferida no Lattes. Uma postura despojada de reflexão crítica acerca do papel do pesquisador na sociedade, reduzido a

\footnotetext{
${ }^{1}$ Coordenação de Aperfeiçoamento de Pessoal de Nível Superior.

${ }^{2}$ Conselho Nacional de Desenvolvimento Científico e Tecnológico.
} 
um mero gestor de projetos e de publicações por meio de cooptações e de um rodízio viciado de coautorias que não poupa, inclusive, o voluntariado discente.

Nesses termos, conceitos e categorias se reduzem a meros apêndices. Recursos figurativos, sem interação aparente com o problema, o objeto e o método. Não cumprem outra função senão a de uma exigência protocolar desprovida de rigor metodológico sob o imperativo do produtivismo e da competitividade. Não há, assim, lugar para a criatividade e muito menos para contemplação de sujeitos na pesquisa, pois tais critérios de produtividade não coadunam com a atitude qualitativa. $\mathrm{O}$ que suprime, além da teoria, a História (com inicial maiúscula mesmo), a poesia e a utopia a pretexto de sua inaplicabilidade. Essa métrica inviabiliza qualquer possibilidade de aprofundamento teórico, pois impõe o emprego de aportes conceituais como um exercício meramente mecânico e tautológico. Sob tais condições, o tempo lento necessário à teoria se acomoda ao just in time da competição, do negócio e da negação do ócio.

Seja por comodismo ou por conveniência, uma das formas mais recorrentes de recorte teórico, se é que se pode qualificá-la assim, é o apanhado cronológico dos conceitos. Geralmente, tal enfoque se restringe a uma exposição histórico-linear acerca do surgimento ou da definição dos conceitos, com poucas derivações de significado entre um trabalho e outro e sem qualquer tipo de coerência no tocante aos problemas e escopo da pesquisa. Isso implica uma postura menos epistemológica do que histórica (repara-se, com inicial minúscula), comprometendo, assim, o tratamento analítico e interpretativo dos fatos em decorrência de ausência de contra-adições na ordem do pensamento. Bachelard (1996, p. 22) menciona, a propósito, que "um fato mal interpretado por uma época permanece, para o historiador [de ciência], um fato. Para o epistemólogo, é um obstáculo, um contra-pensamento". O fatalismo levado a efeito pelo historicismo linear conceitual mostra-se, portanto, uma abordagem cômoda para o geógrafo preocupado mais em colecionar publicações do que produzir conhecimento.

\section{CONSIDERAÇÕES FINAIS}

Os obstáculos enfrentados pela produção teórica em geografia não derivam, no seu conjunto, de uma ou outra fonte específica, sejam tais obstáculos mais visíveis no nefasto legado do positivismo, na imprecisão do pós-modernismo ou nas implicações das políticas de fomento à pesquisa. Todos os casos arrolados acima, porém, parecem derivar de uma condição indispensável para o florescimento da teoria, qual seja: o tratamento epistemológico e o metodológico para com, respectivamente, sua concepção e sua aplicação. Ambas as condições reservam deficiências no tocante à relação entre a teoria e os problemas propostos em cada época e em cada ciência, sem a qual aquela se esvazia na mais pura abstração, quando não estaria completamente ausente. 
Tal vazio não deve ser levado, no entanto, ao pé da letra. Não se sugere, exatamente, que incursões teóricas não estejam sendo atualmente empreendidas. Porquanto se evidencia um reiterado e variado apelo a explanações conceituais como jamais houve na história da geografia. Nossa preocupação é, todavia, menos de ordem quantitativa do que qualitativa. Reside na constatação de que tais aportes teórico-conceituais guardam certas fragilidades no que se refere às suas bases epistemológicas e aos impasses e às questões colocados pela geografia na contemporaneidade.

Os problemas e questões motivadores dos conceitos e categorias estão atrelados ao objeto de cada domínio científico. No caso da geografia, relacionam-se ao espaço em sua interdeterminação com a sociedade e a natureza. Referem-se, portanto, à produção e reprodução, apropriação, organização, diferenciação, degradação, circulação, consumo, dentre inúmeros outros motes pertinentes ao espaço. No plano interno, os conceitos geográficos vinculam-se aos princípios lógicos, ou seja, à localização, distribuição, extensão, distância, posição e escala (MOREIRA, 2008). A epistemologia confronta e articula tais variáveis, dotando-as de fundamento e de coerência e fornecendo instrumentos analíticos para um consequente edifício interpretativo. A negligência para com esses pressupostos resulta num acentuado distanciamento entre teoria e prática.

A dissociação entre teoria e prática deriva, de uma parte, da propensão da teoria em tornarse um fim em si mesma, transparecendo sua face especulativa. De outra parte, alguns estudiosos de reconhecida inclinação prática (em alguns casos, de notável comprometimento político) não escondem seu desprezo pela teoria. Esse insistente dualismo não compreende a práxis como condição ontológica que tensiona e põe em interação a consciência e o ser social. O que nos coloca o desafio de depreender essa contradição em termos de geograficidade, enquanto modo de existir geográfico (MOREIRA, 2004, 2008; SILVA, 2000). Não obstante, a teoria pode comparecer aos espíritos mais pragmáticos como algo que não lhe convém, porquanto não contempla resultados imediatos, logo, não aparenta utilidade. Ignora-se que prática sem teoria é conteúdo sem forma, algo tão abstrato quanto a mais pura especulação teórica.

Ao se renderem à atitude especulativa, os trabalhos de teoria da geografia se voltam para fora, exploram imagens fantásticas e prodigiosas, sistemas filosóficos improváveis e por vezes pouco permeáveis à geografia. Perseguem por toda parte novos horizontes de inteligibilidade para renovar seu método e seu arcabouço conceitual. Alguns poucos obtêm êxito, é bem verdade. Outros nada mais fazem que esvaziar a teoria dos problemas e questões colocados à geografia. Há aqueles ainda que, numa tentativa de superar tais imbróglios, voltam sua atenção para o sujeito ou para a ontologia. Não raro, se perdem em seus meandros terminológico e contemplativo, comprometendo, paradoxalmente e mais uma vez, a vinculação da teoria com a prática. 
Sem soluções aparentes, muitos geógrafos se limitam ao enfoque historiográfico dos conceitos, quando não usam indiscriminadamente conceitos de outras ciências. Nossas objeções a essas abordagens não sugerem, contudo, ignorar por completo tais possibilidades. Até porque conceito nenhum é um ente privativo de qualquer que seja a ciência, embora não se possa dizer o mesmo das questões requeridas por cada uma delas. Todavia, seria prudente não subordinar o discurso geográfico, suas categorias e métodos aos discursos, conceitos e métodos predominantes em outras ciências. Assim, tanto a recuperação histórica dos conceitos quanto a contribuição teórico-conceitual de outros campos científicos cumpririam uma função complementar, afirmando a centralidade da teoria, dos problemas e das questões geográficas.

O presumível esvaziamento teórico na geografia na atualidade não decorre, portanto, da apropriação teórica e metodológica de outros campos, senão de sua subordinação. Também não deriva da sua vocação empirista e tampouco da falta de categorias e conceitos suficientes para subsidiar o discurso geográfico. Pode-se, então, concluir que a teoria geográfica peca por excesso? Absolutamente! Seu pecado capital é voltar-se para si mesma, alhear-se do efêmero, resignar-se ao emprego tautológico. Sua esterilidade oscila entre a fragmentação especializante, o ecletismo celebratório e a lógica da "farinha pouca meu pirão primeiro" do produtivismo institucionalizado. Sua debilidade reside na constatação de que quando mais se produz teoria na história da geografia é quando menos se interpreta e se explica a realidade. Sua miséria está em não refletir sobre as questões de vulto da sociedade contemporânea.

\section{REFERÊNCIAS}

BACHELARD, G. A formação do espírito científico. 1. ed. Rio de Janeiro: Contraponto, 1996. 316p.

CORRÊA, R. L. Produção geográfica, controle e poder. Biblio 3W, Barcelona, v. 11, n. 650, p.1-2, 2006.

CROSS, D.; T, S.; S, A. Research in Brazil: A report for CAPES by Clarivate Analytics. Philadelphia: Clarivate Analytics, 2018. 73p.

GIBSON, C.; KLOCKER, N. Academia Publishing as 'Creative' Industry and Recent Discourses of 'Creative Economies': Some Critical Reflections. Area. Institute of British Geographers, v. 36, n. 4, p. 423-434, 2004.

GUIMARÃES, H. G.; LIMA, E. L. Os fundamentos ontoepistemológicos da geografia frente às fragmentações teóricas e práticas. In: ENCONTRO NACIONAL DA ANPEGE, 12., 2017, Porto Alegre. Anais... Porto Alegre: ANPEGE, 2017. p.1-4.

HARVEY, D. A condição pós-moderna: uma pesquisa sobre as origens da mudança cultural. São Paulo: Loyola, 1989. 352p. 
HISSA, C. E. V. Entrenotas: compreensões de pesquisa. 1. ed. Belo Horizonte: Ed. UFMG, 2013. $197 \mathrm{p}$.

MARTINS, É. R. O pensamento geográfico é geografia em pensamento? GEOgraphia, Niterói, v. 18, n. 37. p. 61-79, 2016.

MOREIRA, R. Marxismo e geografia: a geograficidade e o diálogo das ontologias. GEOgraphia, Niterói, v. 6, n. 11, p. 21-37, 2004.

. Pensar e ser em geografia. 2. ed. São Paulo: Contexto, 2008. 190p.

- Geografia e práxis: a presença do espaço na teoria e na prática geográficas. 1. ed. São Paulo: Contexto, 2012. 222p.

. O discurso do avesso: para a crítica da geografia que se ensina. 1. ed. São Paulo: Contexto, 2014. 190p.

PORTO-GONÇALVES, C. W. A globalização da natureza e a natureza da globalização. 2. ed. Rio de Janeiro: Civilização Brasileira, 2015. 462p.

SANTOS, M. A natureza do espaço: Técnica e tempo. Razão e emoção. 1. ed. São Paulo: Hucitec, 1996. 232p.

SHORT, J. R. The Disturbing of the Concentration of Power in Human Geography. Area. Institute of British Geographers, v. 34, n. 2, p. 323-324, 2002.

SILVA, A. C. A Aparência, o Ser e a Forma (Geografia e Método). GEOgraphia, Niterói, v. 2, n. 3, p. 7-25, 2000.

SOUSA NETO, M. F. A expansão financerizada do ensino superior e da pós-graduação no Brasil. Revista ANPEGE, v.13, n.20, p.18-29, 2017.

THOMPSON, E. P. A miséria da teoria ou um planetário de erros: uma crítica ao pensamento de Althusser. 1. ed. Rio de Janeiro: Zahar Editores, 1981. 260p. 